\title{
四鹽化エタンの接觸的脫鹽酸分解について（第二報） 同分解に現扎る反應次數
}

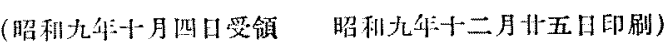

III四期

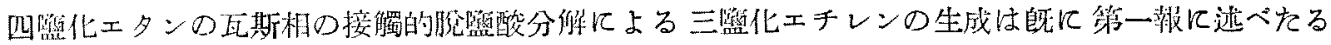

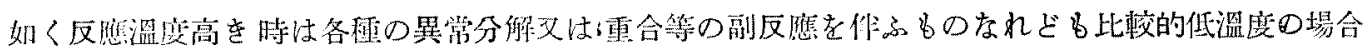

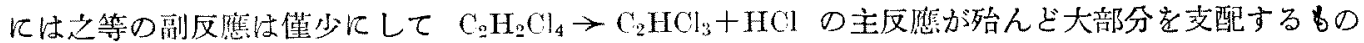

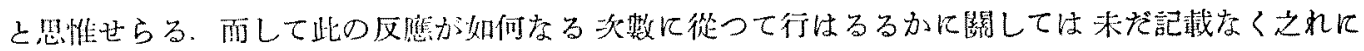
つを實驗せし所を報告せんとす

\section{裝 置}

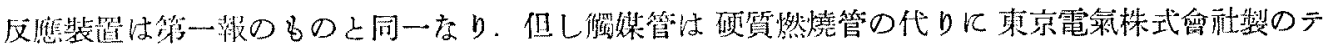
レックス确子管闪得 $14 \mathrm{~mm}$ のものを使脚せり

\section{反應生成物中の $\mathrm{C}_{2} \mathrm{HCl}_{3}$ の定量}

不鸽和化合物定量の常踏法なるハロダンの扣成に閶しては既にK.A.

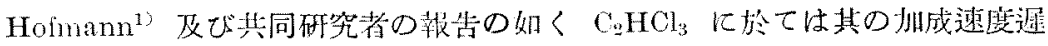



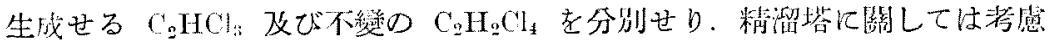

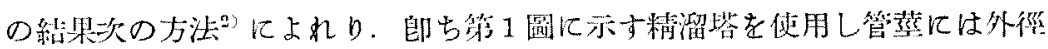

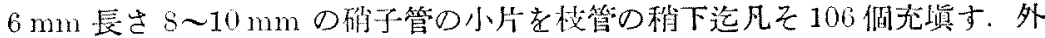

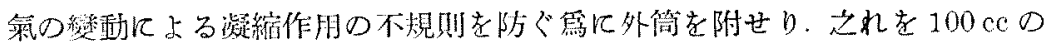

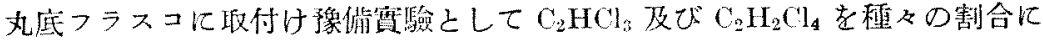

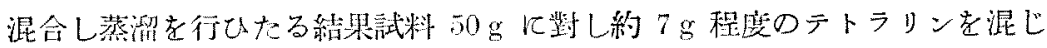

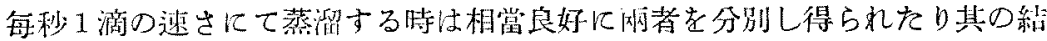
果沃の如し.

\begin{tabular}{|c|c|c|c|c|}
\hline \multirow{2}{*}{$\begin{array}{c}\text { テトラリン } \\
(\mathrm{g})\end{array}$} & \multicolumn{2}{|c|}{ 試 $(g)^{\text {料 }}$} & \multicolumn{2}{|c|}{$\begin{array}{l}\text { 教 } \\
\text { (g) }\end{array}$} \\
\hline & $\mathrm{C}_{2} \mathrm{HC} l_{3}$ & $\mathrm{C}_{2} \mathrm{H}_{2} \mathrm{Cl}_{4}$ & $\mathrm{C}_{2} \mathrm{HCl}_{3}$ & $\mathrm{C}_{2} \mathrm{H}_{2} \mathrm{Cl}_{4}$ \\
\hline 0 & 40 & 10 & 38 & 5 \\
\hline 50 & 40 & 10 & 39 & 5 \\
\hline 10 & 40 & 10 & 38 & 7.5 \\
\hline 7 & 40 & 10 & 39 & 9 \\
\hline 7 & 30 & 20 & 29 & 19 \\
\hline 7 & 20 & 30 & 19 & 29 \\
\hline 7 & 10 & 40 & 9.5 & 39 \\
\hline
\end{tabular}

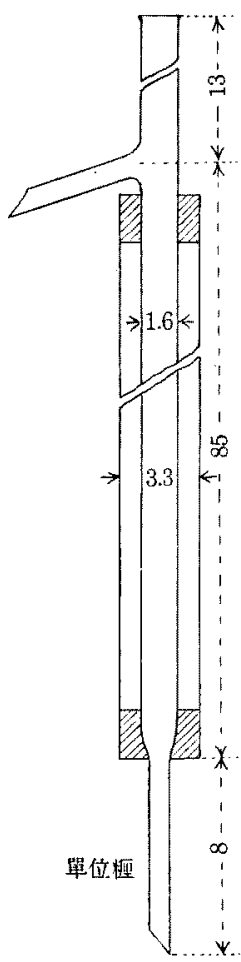

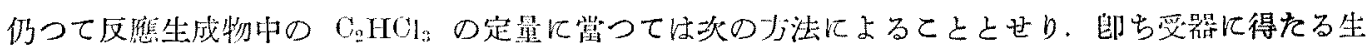

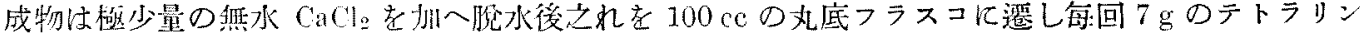

1) K. A. Hofmann, H. Kirmreuther: Ber., 42 (1909), 4484. 413 老參考す。

2) H. Brückner: Chem. Ztg. 40 (1984), 


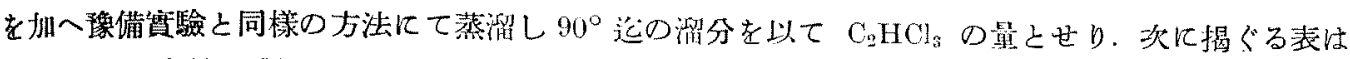
各比觸媒屏長 $(l)$ 飞對する $\mathrm{C}_{3} \mathrm{HCl}_{3}$ の收量を表したるものにして曲線 $\mathrm{I}$ は反礁㴓度 $200^{\circ}$ の場合，曲 線 II は $250^{\circ}$ の場合な D.

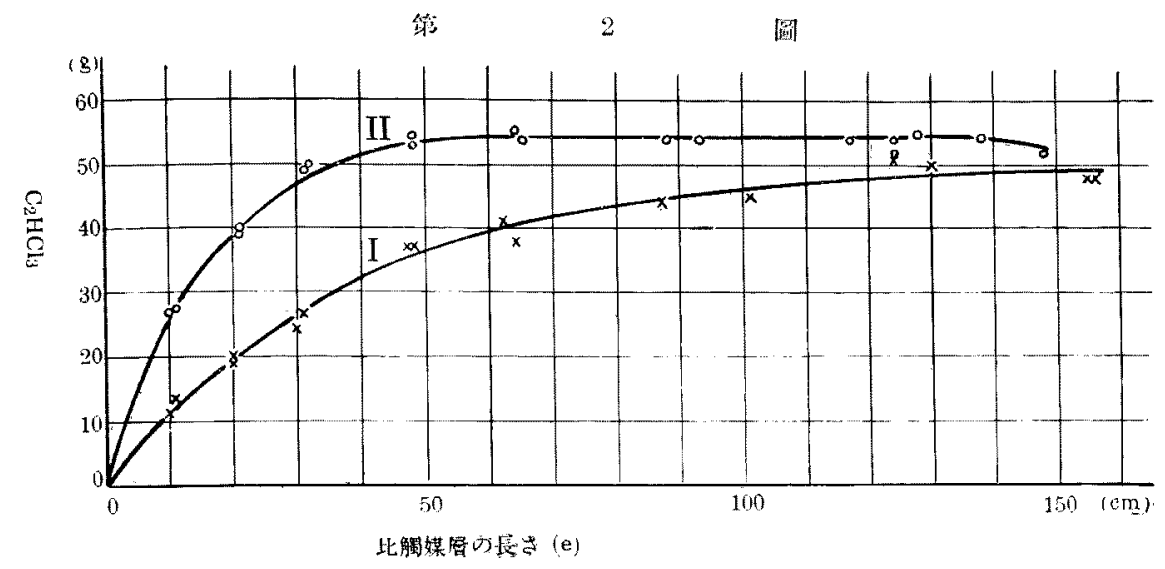

\section{反 應 次 數 $の$ 計 算}

一般の反應速度方程式に從ひ $a$ を物質最初の量とし $x$ 孝時間 $t$ の後に於ける變化量とせげ

$$
\begin{aligned}
\text { 一大反雇 } & \frac{d x}{d t}=k(a-x) & \therefore & k=\frac{1}{t} \ln \frac{a}{a-x} \\
\text { 二次反應 } & \frac{d x}{d t}=k(a-x)^{2} & \therefore & k=\frac{1}{t} \cdot \frac{x}{a(a-x)}
\end{aligned}
$$

此の場合 $t$ は觸媒に接觸する時間にして觸媒虚の長され比例すべし. 然るに各回 $\mathrm{C}_{2} \mathrm{H}_{2} \mathrm{Cl}_{4} 84 \mathrm{~g} の$

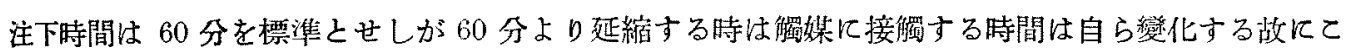

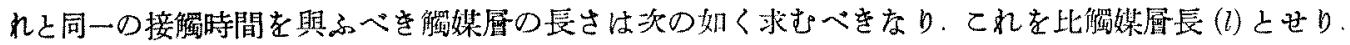

$$
l(\mathrm{~cm})=\frac{\text { 注下㭙間 }(\text { 分 })}{60 \text { 分 })}
$$

從つて前式に於ける $t$ は $l$ 比例すべ，仍つて反應速度恒數 $k$ は次の如し.

一次反應 $\quad k_{1} \times 0.43=\frac{1}{l} \cdot \log \frac{a}{a-n}$

二次反應 $\quad k_{\mathrm{g}} \times a=\frac{1}{l} \cdot \frac{x}{a-x}$

\begin{tabular}{|c|c|c|c|c|c|c|c|c|c|c|c|}
\hline 番號 & $l$ & ( $90^{\circ}$ 迄) & $x$ & $k_{1} \times 0.43$ & $k_{2} \times a$ & 番號 & $l$ & $\left(90^{\circ}\right.$ 沦) & $x$ & $h_{1} \times 0.43$ & $k_{2} \times \mathrm{a}$ \\
\hline 38 & 0 & 0 & 0 & - & - & 21 & 48 & 37.0 & 47.5 & 77 & 27 \\
\hline 40 & 0 & 0 & 0 & - & - & 12 & 62 & 41.0 & 52.5 & 69 & 27 \\
\hline 34 & 10 & 11.5 & 15.0 & 0.0093 & 0.022 & 9 & 64 & 38.0 & 48.5 & 59 & 21 \\
\hline 35 & 11 & 13.5 & 17.5 & 91 & 24 & 5 & 87 & 44.0 & 56.0 & 55 & 23 \\
\hline 29 & 20 & 19.0 & 24.0 & 73 & 20 & 1 & 101 & 45.0 & 57.5 & 49 & 22 \\
\hline 33 & 20 & 20.0 & 26.0 & 79 & 22 & 43 & 124 & 51.0 & 65.0 & 52 & 28 \\
\hline 24 & 30 & 24.5 & 31.5 & 68 & 20 & 42 & 130 & 50.0 & 64.0 & 48 & 25 \\
\hline 25 & 31 & 27.0 & 34.5 & 74 & 23 & 14 & 155 & 48.0 & 61.5 & 37 & 18 \\
\hline 20 & 47 & 37.0 & 47.5 & 77 & 28 & 13 & 156 & 48.0 & 61.5 & 37 & 18 \\
\hline
\end{tabular}

又 $a=84$ にして $x$ は生成せる $\mathrm{CgHCl}_{3}$ 亿相虽する $\mathrm{C}_{2} \mathrm{H}_{2} \mathrm{Cl}_{4}$ の量なれば $x=\left(90^{\circ}\right.$ 迄 $) \times \frac{168}{131.5}$ なり. 今 $200^{\circ}$ K於ける $k$ の值を計算せる結果次の如し. 
以上の結果を見るにkの值は良好なる一致牥示し居らさるも $k_{2}$ に於て稍近を恒數を示し $\mathrm{C}_{2} \mathrm{H}_{2} \mathrm{Cl}_{4}$ の瓦斯相に於ける活性炭の接触的脫笽酸分解は二次反應儿進行すると見るを至當とすへし，仍つて

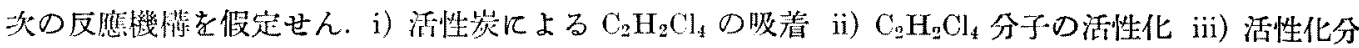
子二分子間の反隹による分解 $2 \mathrm{C}_{2} \mathrm{H}_{2} \mathrm{Cl}_{4}=2 \mathrm{C}_{2} \mathrm{HCl}_{3}+2 \mathrm{HCl}$ 而して反應速度は iii）の段程に於て定ま るものとす。

$250^{\circ}$ に於ける速度恒數 $k$ については $200^{\circ}$ の場合よりも一致不良にて且つ曲線の平衡部に達する $l$ 短くしてkの汒定困難なるが故に記戴せざりき.

實 驗 $\quad$ 部

\begin{tabular}{|c|c|c|c|c|c|c|c|c|c|}
\hline \multirow{2}{*}{ 䅎號 } & \multirow{2}{*}{ 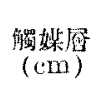 } & \multirow{2}{*}{$\frac{\left({ }^{\circ} \mathrm{C}\right)}{\mathrm{C}}$} & \multirow{2}{*}{$\begin{array}{c}\text { 注下時間 } \\
\text { (分) }\end{array}$} & \multirow{2}{*}{$\begin{array}{c}\text { 生成物 } \\
(\mathrm{g})\end{array}$} & 分 & 溜 & 繈 & (g) & \multirow{2}{*}{$l(\mathrm{~cm})$} \\
\hline & & & & & $90^{\circ}$ 茫 & $120^{\circ}$ 范 & $140^{\circ}$ 汽 & $140^{\circ}$ 以上 & \\
\hline 1 & 80 & $200^{\circ}$ & 76 & 63.5 & 45.0 & 4.0 & 4.0 & 8.5 & 101 \\
\hline 3 & 80 & $250^{\circ}$ & 66 & $63 . \tilde{5}$ & 54.0 & 7.5 & - & - & 88 \\
\hline 4 & 80 & $250^{\circ}$ & 70 & 63.0 & 54.0 & 8.0 & - & - & 93 \\
\hline 5 & 80 & $200^{\circ}$ & 65 & 63.5 & 44.0 & 6.0 & 3.0 & 7.0 & 87 \\
\hline 9 & 60 & $200^{\circ}$ & 64 & 66.0 & 38.0 & 4.5 & 5.0 & 17.0 & 64 \\
\hline 10 & 60 & $250^{\circ}$ & 64 & 63.5 & 55.5 & 6.5 & - & - & 64 \\
\hline 11 & 60 & $250^{\circ}$ & 65 & 63.0 & 54.0 & 8.0 & - & - & 65 \\
\hline 12 & 60 & $200^{\circ}$ & 62 & 67.0 & 41.0 & 4.5 & 4.0 & 17.0 & 62 \\
\hline 13 & 60 & $200^{\circ}$ & $156^{\circ}$ & 58.5 & 48.0 & 5.5 & 3.5 & - & 156 \\
\hline 14 & 60 & $200^{\circ}$ & 155 & 61.0 & 48.0 & 3.0 & 3.5 & 2.0 & 155 \\
\hline 17 & 60 & $250^{\circ}$ & 138 & 63.0 & 54.5 & 4.0 & 4.0 & - & 138 \\
\hline 18 & 60 & $250^{\circ}$ & 148 & 61.0 & 52.0 & 4.0 & 4.0 & - & 148 \\
\hline 19 & 60 & $250^{\circ}$ & 117 & 63.0 & 54.0 & 4.0 & 4.5 & - & 117 \\
\hline 20 & 45 & $200^{\circ}$ & 63 & 61.0 & 37.0 & 4.0 & 3.5 & 16.5 & 47 \\
\hline 21 & 45 & $200^{\circ}$ & 64 & 64.0 & 37.0 & 4.0 & 3.5 & 19.0 & 48 \\
\hline 22 & 45 & $250^{\circ}$ & 64 & 62.5 & 53.0 & 3.5 & 4.5 & - & 48 \\
\hline 23 & 45 & $250^{\circ}$ & 64 & 63.5 & 54.5 & 3.5 & 4.5 & - & 48 \\
\hline 24 & 30 & $200^{\circ}$ & 60 & 71.0 & 24.5 & 3.0 & 5.0 & 38.0 & 30 \\
\hline 25 & 30 & $200^{\circ}$ & 61 & 72.0 & 27.0 & 3.0 & 3.0 & 38.0 & 31 \\
\hline 26 & 30 & $250^{\circ}$ & 61 & 63.0 & 50.0 & 6.0 & 4.0 & 2.0 & 31 \\
\hline 27 & 30 & $250^{\circ}$ & 63 & 63.5 & 50.0 & 7.0 & 2.0 & 2.0 & 32 \\
\hline 29 & 20 & $200^{\circ}$ & 60 & 73.5 & 19.0 & 2.5 & 3.0 & 48.0 & 20 \\
\hline 30 & 20 & $250^{\circ}$ & 62 & 67.5 & 39.0 & 4.0 & 3.0 & 21.0 & 21 \\
\hline 31 & 20 & $250^{\circ}$ & 62 & 67.5 & 40.0 & 3.0 & 5.0 & 20.0 & 21 \\
\hline 33 & 20 & $200^{\circ}$ & 60 & 75.5 & 20.0 & 3.0 & 3.0 & 48.0 & 20 \\
\hline 34 & 10 & $200^{\circ}$ & 60 & 76.0 & 11.5 & 25 & 2.0 & 59.0 & 10 \\
\hline 35 & 10 & $200^{\circ}$ & 64 & 76.5 & 13.5 & 3.5 & 3.0 & 54.5 & 11 \\
\hline 36 & 10 & $250^{\circ}$ & 63 & 70.0 & 27.5 & 4.0 & 4.0 & 28.0 & 11 \\
\hline 37 & 10 & $250^{\circ}$ & 61 & 69.5 & 27.0 & 4.0 & 3.0 & 25.0 & 10 \\
\hline 38 & 0 & $200^{\circ}$ & 63 & 84.0 & - & - & - & 84.0 & 0 \\
\hline 39 & 0 & $250^{\circ}$ & 60 & 84.0 & - & - & - & 84.0 & 0 \\
\hline 40 & 0 & $200^{\circ}$ & 60 & 83.5 & - & - & 3.5 & 80.0 & 0 \\
\hline 41 & 0 & $250^{\circ}$ & 67 & 83.5 & - & - & 3.5 & 80.0 & 0 \\
\hline 42 & 60 & $200^{\circ}$ & 130 & 63.0 & 50.0 & 8.0 & 4.0 & - & 130 \\
\hline 43 & 60 & $200^{\circ}$ & 124 & 63.0 & 51.0 & 6.0 & 4.0 & - & 124 \\
\hline 44 & 60 & $250^{\circ}$ & 124 & 62.0 & 52.0 & 9.0 & - & - & 124 \\
\hline 45 & 60 & $250^{\circ}$ & 124 & 62.0 & 54.0 & 7.0 & - & - & 124 \\
\hline 46 & 60 & $250^{\circ}$ & 128 & 61.0 & 55.0 & 5.0 & - & - & 128 \\
\hline
\end{tabular}

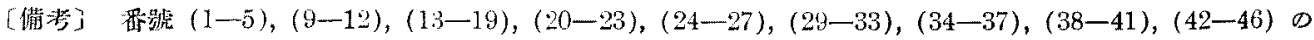
各組每に活性炭を新しく充嚗して赛橓せり。

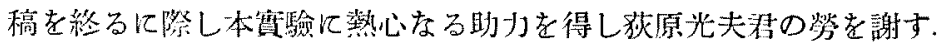

(長岡高學工業學校化學敎室) 